International Journal of English Literature and Social Sciences
Vol-6, Issue-1; Jan-Feb, 2021

\title{
The Gender Dimension of Plagiarism: A Case Study
}

\author{
John Vincent A. Pagaddu
}

College of Arts and Sciences, University of the Philippines Manila

Received: 03 Nov 2020; Received in revised form: 18 Jan 2021; Accepted: 01 Feb 2021; Available online: 16 Feb 2021

C2021 The Author(s). Published by Infogain Publication. This is an open access article under the CC BY license

(https://creativecommons.org/licenses/by/4.0/).

\begin{abstract}
Many studies on plagiarism have suggested that there exist gender differences in the extent of plagiarizing in education. It is therefore the purpose of this paper to determine the different reasons why students engage in plagiarism and to describe any gender differences in the reasoning of the students. In this present paper, a total of thirty college students (fifteen males and fifteen females) of the College of Arts and Sciences (CAS), University of the Philippines Manila were included. A semi-structured survey questionnaire was used in this study and descriptive statistical tools were used to characterize the study population. Based on the findings of this study, males and females practice plagiarism on a similar level. However, their reasons of plagiarizing are very different.
\end{abstract}

Keywords—academics, gender difference, plagiarism, plagiaristic practice.

\section{INTRODUCTION}

Nowadays, cases of plagiarism are steadily increasing, and this is worsened by an easy access to the online resources (Harris, 2001; Park, 2003). Students could easily access internet and download articles and other related sources, which, as a result, tempt them to copy work of others and transform them as their own. Aside from having an easy access to the internet, one of the primary reasons why cases of plagiarism are continuously increasing and are inevitable is that many are still not aware of what plagiarism is. According to R.A. Harris (2001), the author of The Plagiarism Handbook, "adapting ideas, sentences, paragraphs ... . or other intellectual properties that are not regarded as general knowledge must be cited in an appropriate manner." If one happens not to properly cite sources, then it is already considered plagiarism.

Many studies have already attempted to reveal the plagiaristic practices done by students. It only implies that many people are concerned with academic integrity in the industry of education (Fa'iezah, 2008). However, none of them concerns about finding out the different reasons of each gender toward plagiarism. Hence, it is the purpose of the present paper to discuss plagiarism as a form of academic dishonesty and, especially, gender as a variable of plagiarism. Primarily, the aim of this investigation was to determine the different reasons why students engage in plagiarism and to describe any gender differences in the reasoning of the students.

Data from this paper could provide information about the differences of the reasons of why male and female students resort to plagiarism, and, thus, this may serve as a reference to different institutions in giving solutions to the persisting problem on plagiarism.

\section{METHODOLOGY}

This paper studied the differences on the reasoning of both gender in committing plagiarism. This paper utilized a survey questionnaire, which was patterned on the questionnaires made by Fa'iezah (2008) for his study on "Gender Difference in Plagiarism Attitudes among Indonesian University students in Perth Australia." Due to time constraints, convenience sampling was chosen as the most suitable approach in this paper. A total of thirty (30) college students, fifteen (15) males and fifteen (15) females, who were enrolled in Second Semester A.Y. 2011-2012 in the College of Arts and Sciences, University of the Philippines Manila were included and asked to answer the survey questions. All the respondents were clearly informed of the objectives and the significance of the study. Also, informed consent was obtained from all the respondents prior to the conduct of the survey. The 
participants were instructed to answer all the questions of the survey. After all the survey questionnaires were received, the data were immediately tabulated and analyzed.

\section{RESULTS AND DISCUSSION}

This paper studied the gender reasoning differences of plagiarism in relation with the differences in behaviour, in way of thinking, and in moral reasoning and views between male and female students. It utilized a survey questionnaire, which was distributed to both male and female respondents, in equal numbers, in different age brackets and year levels. Through convenience sampling, data were gathered and then evaluated in order to determine the variables needed in the study.

Table 1. Percent Distribution of Male's and Female's definition of plagiarism $(N=30)$

\begin{tabular}{|c|c|c|c|}
\hline $\begin{array}{c}\text { Definition of } \\
\text { plagiarism }\end{array}$ & $\begin{array}{c}\text { Female } \\
\text { s }\end{array}$ & $\begin{array}{c}\text { Male } \\
\text { s }\end{array}$ & Total \\
\hline $\begin{array}{c}\text { Paraphrasing concepts } \\
\text { without citation }\end{array}$ & $30 \%$ & $20 \%$ & $\mathbf{5 0 \%}$ \\
\hline $\begin{array}{c}\text { Changing the sentence } \\
\text { structure of the } \\
\text { concept }\end{array}$ & $6.67 \%$ & $0 \%$ & $\mathbf{6 . 6 7 \%}$ \\
\hline $\begin{array}{c}\text { Dropping quotation } \\
\text { marks when copying } \\
\text { the concepts verbatim } \\
\text { but with } \\
\text { acknowledgement of } \\
\text { author }\end{array}$ & $10 \%$ & 6.67 \\
$\%$ & $\mathbf{1 6 . 6 7}$ \\
\hline $\begin{array}{c}\text { Using an essay bank or } \\
\text { a term paper mill }\end{array}$ & $3.33 \%$ & 16.67 & $\mathbf{2 0 \%}$ \\
\hline $\begin{array}{c}\text { Using citation in every } \\
\text { paraphrase and direct } \\
\text { quotation }\end{array}$ & $0 \%$ & 6.67 & $\mathbf{6 . 6 7 \%}$ \\
\hline
\end{tabular}

Using the survey questionnaires, students were asked which of the given definitions described plagiarism best. As shown in Table 1, most of the respondents (50\%) favored "Paraphrasing concepts without citation" as the definition of plagiarism. Out of this proportion, $30 \%$ were females and 20\% were males. According to Park (2003), paraphrasing the concepts of someone without proper acknowledgement of the author is the most common form of plagiaristic act performed by university students. This could be attributed to the ignorance of students toward committing plagiarism (Harris, 2001). Based on the obtained data, 21 respondents said they never realized that they were actually plagiarizing, and this number was dominated by females $(52 \%)$. Also, half of the respondents reported that they have no idea about plagiarism. Majority $(60 \%)$ of them were females.

Majority (90\%) of the respondents believed that males are more likely to commit plagiarism. This result reflects a possible gender dimension in plagiarism. According to a body of research, males are more likely to plagiarize because of their high educational expectations. The association of males with plagiarism may also be attributed to their bravery, which is indeed the reason why males regard moral values with less consideration (Whitley et al., 1999). On the other hand, morality is the most influential thing that affects the lives of females. Indeed, females are considered to be the good models in each household, and that they always tend to consider their emotions in decision-making. More often than not, females based their decisions on their moral grounds. As such, it is more difficult for them to decide on whether to do plagiarism or not.

In this paper, 8 of 15 respondents who believed that plagiarism is a sin were females. In general, a higher sense of morality is attributed to females, which could have been the reason why none of the female respondents of this study said that females are more likely to plagiarize.

Most male respondents $(87 \%)$ said that they lack priority on their requirements. In fact, $93 \%$ of male respondents do their requirements a day or three prior to the deadline. This is a possible reason why males procrastinate. According to the study done by Roig and De Tommaso (1995), males tend to procrastinate more compared to females, and males are more likely to plagiarize because of procrastination.

Because of time constraints and pressure, males are more likely to plagiarize and do direct substitution in order to meet the deadline set by their professors and to achieve their high academic expectations. In this paper, $67 \%$ of male respondents said that they have already done direct substitution of someone else's work. Moreover, 97\% of the total respondents said that time pressure is a reason why they do plagiarism.

In another perspective, the lack of priority of males on their requirements may have been the result of their heavy workload. The findings of this present paper revealed that all of the male respondents agreed that heavy workload caused them to plagiarize. Heavy workload could have been the reason why males tend to have little time allotted for doing their requirements. Females are also subject to heavy workload. Nevertheless, a body of scientific research have suggested that females can multitask more than males do. Hence, female students can still manage their time despite a heavy workload. This is one of the 
possible factors why females are less likely to be pressed by time.

\section{CONCLUSIONS}

Based on the findings, males and females practice plagiarism on a similar level. However, their reasons of plagiarising are very different. This study therefore concludes that gender reasoning is primarily affected by behavioral differences. Multitasking is a big factor that may affect both genders in managing their time. Furthermore, traits attributed to each gender, such as ignorance, indolence, and inability to manage time could be the main sources of plagiaristic act.

\section{RECOMMENDATIONS}

This paper recommends further investigation on the reasons why students do not consider plagiarism as a grave problem. To get a deeper and more accurate result about this study, a qualitative research should be conducted. Also, future researchers must consider interviewing students.

\section{ACKNOWLEDGEMENT}

As a graduate of the College of Arts and Sciences of the University of the Philippines Manila, I expressed my profound gratitude to this institution which paved my way and gave me golden opportunities in the field of research.

Also, I would like to acknowledge the guidance which I have received from my professor in Communications II, Ms. Pam Yu, whose expertise, suggestion and constructive criticism have contributed greatly to the consolidation of ideas in this paper.

I would also want to extend my appreciation to Tito A. Addun Jr. for supporting me in this endeavor. Lastly, I am really thankful to my parents and siblings who have always been supportive of my undertakings.

\section{REFERENCES}

[1] Fa'iezah, L. U. (2009). Gender Differences in Plagiarism Attitudes among Indonesian University Students in Perth Australia. Retrieved on January 25, 2012 from http://hdl.handle.net/10179/2252

[2] Harris, R.A. (2001). The Plagiarism Handbook: Strategies for Preventing, Detecting, Dealing with Plagiarism. United States of America: Pyrozak Publishing.

[3] Park, C. (2003). In other (People's) Words: Plagiarism by University Students - Literature and Lessons. Assessment and Evaluation in Higher Education, 28 (5): 471 - 488.
[4] Roig, M. and De Tommaso, L. (1995). Are College Cheating and Plagiarism Related to Academic Procrastination? Psychological Report, 11: 307 - 324.

[5] Whitley, B.E., Nelson, A.B. \& Jones, C.J. (1999). Gender Differences in Cheating Attitudes and Classroom Cheating Behavior: A Meta-Analysis. Sex Roles, 41, 657-667. 